\title{
The Status Quo of Zunyi Tourism Industry and Its Development Strategy Xu Guo ${ }^{1, a}$, Shanshan Liu ${ }^{1, b}$, Longjian Sun ${ }^{1, c}$ \\ ${ }^{1}$ School of Economics, Guizhou University of Commerce, Guiyang, 550014, China \\ aemail: guoxu408@163.com, ${ }^{\text {bemail: 313026599@qq.com, }{ }^{c} e m a i l: 75955191 @ q q . c o m}$
}

Keywords: tourism; Zunyi; tourism industry; development strategy

\begin{abstract}
Tourism industry is regarded as the engine for regional economic and social development. Hence, Zunyi municipal government regards tourism as important strategy for the development of the second largest city in Guizhou Province, Southwest China. The article, makes an analysis of Zunyi's tourism environment and resources, describes its developing circumstance, summarizes the basic features of Zunyi tourism industry, explores its development pattern, and puts forward the strategy and countermeasures for Zunyi tourism industry.
\end{abstract}

\section{Introduction}

The tourism industry is the largest industry in the world and plays an important role in promoting the economic development, social progress and people's well-being of various countries and regions [1-4]. In recent years, China's tourism industry has made great progress, a large number of related research emerged. Such high-level research ranges from attracting international investment [5], history and cultural village tourism [6], to tourism industry sustainable development [7], tourism industry development strategy change [8], and regional tourism revenue [9] and so on. In order to provide local tourism research for China, this article will focus on the development of tourism industry in Zunyi.

On the study of tourism industry in Zunyi, there is no English literature, and only a small number of Chinese literatures explore this issue. This article mainly adopts the single case study method, carries on empirical research on Zunyi's tourism industry development. The article makes an analysis of Zunyi's tourism environment and resources endowment, describes its developing circumstance, summarizes the basic features of Zunyi tourism industry, explores its development pattern, and puts forward the strategy and countermeasures for Zunyi tourism industry.

\section{Resources Endowment of Zunyi Tourism Industry}

Located in the north of Guizhou Province, Zunyi is an important city in the Southwest China and a national tourism demonstration area. Zunyi's economic output ranks only second to Guiyang, the capital city of Guizhou Province. Zunyi completed GDP of 216.83 billion yuan in 2015, realizing a year-on-year growth of $13.2 \%$, an average annual increase of $15 \%$. Particularly affected by the monsoon, Zunyi belongs to subtropical monsoon climate area, where there is year-round cool and humid without cold winter and hot summer, but with abundant rainfall and sunshine. The natural landscape formed by Guizhou's special geological structure constitutes the important resource for Zunyi tourism industry. Zunyi contains two districts, eight counties, two autonomous counties and two county-level cities. By the end of 2015, 6.2 million residents populates in Zunyi. There are various types of schools, colleges and universities of 2923, covering 69,800 teachers and 1.3369 million students. There are 36 ethnic minorities, such as Gelao, Miao, Tujia, Buyi, Yi, Dong and Hui, generating the original multi-ethnic culture, which is the cultural condition for tourism industry. Furthermore, Zunyi City also is a regional transportation hub in Southwest China.

The following is the favorable conditions for the development of Zunyi tourism industry.

First, Zunyi owns unique and rich eco-tourism resource. Warm and humid climate makes Zunyi a tourism destination that can be visited throughout the year. This tourism suitability is the endowment of its climate resource. In the urban area, there are many famous scenic spots such as 
Mount. Phoenix Forest Park, Zunyi Botanical Garden, San Ge Park, Nanling City Park, Zunyi Zoo and so on. In other counties and county-level cities, eco-tourism resource also is uniquely distributed, the most famous of which is the Danxia landform and Alsophila spinulosa Nature Reserve in Chishui, a county-level city in Zunyi. Besides, Wujiang Canyon and Chishui River Basin also are representatives of Zunyi's eco-tourism resource.

Second, Zunyi occupies rich Red Culture tourism resource. Red Culture is the prerequisite and foundation of red tourism, as well as the core and vitality of red tourism. Red Culture resource is the unique feature of Zunyi's red tourism. According to 2004-2010 National Red Tourism Development Plan, China planned to cultivate 12 Key Red Tourism Areas, creating them to be impressive vacation destinations at home and abroad, with clear theme, smooth traffic, service facilities, and strong attractiveness. Among them, the Qian(the short name of Guizhou Province)bei Qianxi Red Tourism Area, with theme of "a turning point in history, a successful surprise vaid", centers on Zunyi. Zunyi Meeting Memorial Hall, Martyrs Memorial Park on Red Army Mountain, Red Army Martyrs Monument, Deng Ping Tombs, Red Army encampment along the Long March, leaders' old residence, battle sites, and battlefield relics all become unique resources for Zunyi red tourism development.

Third, Zunyi embraces rich and colorful folk customs. The numerous ethnic groups and their rich colorful folk customs are the advantages of Zunyi tourism industry. The marriage customs of Miao in Meitan area and the performance of Cai Yueliang (a dance style together with playing reed-pipe wind instrument) of Miao in Renhuai have been collected in Non-material Cultural Heritage Protection Directory in Guizhou Province. In the long historical process, the ethnic minorities created and accumulated rich and splendid culture, deeply integrating into their life etiquette such as marriage and funeral, which become important circumstances for people to experience exotic customs. Furthermore, the wide variety of snacks also attracts many visitors. In addition, a number of emerging folk issues, such as Maotai Water Worship Festival sponsored by Renhuai municipal government, combining brewing, water culture, and worship culture together has become a highlight of Zunyi, attracting a lot of tourists.

Fourth, Zunyi tourism wins government and policy support. At the national level, China's tourism policy strongly promotes the development of tourism industry. In the 21st century, China attaches more importance to tourism development. The National Tourism Administration issued a series of laws and regulations to improve the tourism market, such as the State Council Notice on Further Accelerating the Development of Tourism (2001), the State Council Opinions on Accelerating the Development of Tourism (2009), Tourism Law of the People's Republic of China (2013), Several Opinions of the State Council on Promoting the Reform and Development of Tourism Industry (2014). At the provincial level, policies such as the Opinions on Accelerating the Development of Tourism (2001) and the General Plan for Tourism Development in Guizhou Province (2002) were published; the Guizhou Eco-Cultural Tourism Development Plan and the Twelfth Five-Year Plan for Guizhou Tourism were carried out as strong driving forces for the development of Zunyi tourism. At the level of Zunyi City, the municipal government attaches great importance to the construction of tourist attractions, prepares solid foundation for tourism development, and provides policy support in terms of industrial planning, policies and regulations for the development of the tourism industry.

\section{The Status Quo of Zunyi Tourism Industry}

In terms of distribution of tourism resources, Zunyi tourism resources could be divided into three major categories of natural ecology, cultural landscape and social resources, 40 varieties, and more than 100 scenic spots, including 14 state-level spots and 75 provincial spots. Zunyi has 1 world-level natural heritage (Chishui Danxia), 7 scenic spots (including 1 national-level scenic spots and 6 provincial-level spots), 8 Nature Reserves (including 3 national nature reserves), 8 Forest Parks (4 national forest parks and 4 provincial level), 1 national geological park, and 6 national AAAA-level tourist attractions. There are 13 historical sites (including 3 state-level and 10 provincial-level ones), 7 provincial-level museums, 6 ancient tombs (including 1 state-level and 5 
provincial-level temples), 5 historical and cultural cities (towns) (one of which belongs to national level), and 85 red tourist attractions have been brought into the tourism development plan. In addition, Zunyi also owns one leisure agriculture and rural tourism demonstration county and four demonstration sites.

Zunyi achieves continuous growth in tourism overall layout and achievements. In 2010, Zunyi received 16.6231 million tourists, and achieved comprehensive tourism revenue of 14.083 billion yuan, respectively realizing an average annual increase of $38.3 \%$ and $56.3 \%$. 65 tourist attractions were developed, including 23 A-level tourist attractions and 21 above provincial-level tourism demonstration sites. In 2012, Zunyi established strategic cooperation with Guizhou Provincial Tourism Bureau, successfully held the city's First Tourism Industry Development Conference, the Fourth International Mountain Outdoor Sports Challenge, and launched the fine tourism line of "Red Tourism Destination in Zunyi, Pretty Danxia Scenery in Chishui". 29 new tourism projects were started, 33.54 million tourists arrived, and a comprehensive income of 31.2 billion yuan was achieved. In 2013, Zunyi received 43.02 million tourists, total tourism income of 35.9 billion yuan, an increase of $28.3 \%$ and $28.2 \%$ respectively. In 2014, Zunyi City, three new 4A-level scenic spots were launched, eight four-star hotels were built, 51.763 million tourists came and brought tourism revenue of 44.44 billion yuan, respectively an increase of $20.3 \%$ and $24.5 \%$. In 2015, Zunyi municipal government took hosting the Eleventh Tourism Development Conference as an opportunity to vigorously develop the cultural tourism as the leading modern service industry, and achieved positive results. In 2015, 62 million visitors arrived and brought a comprehensive income of 54.7 billion yuan.

Holiday tourism has become the growth point of Zunyi tourism industry. The New Year's Day holiday brought a total of 698,000 tourists to Zunyi, to achieve comprehensive tourism revenue of 513 million yuan, an increase of $24.1 \%$ and $26.7 \%$. During the Golden Week of the Spring Festival holiday, Zunyi received a total of 2.154 million tourists, an increase of 41.4, tourism revenue of 980 million yuan, an increase of $44.1 \%$, ticket sales of 45.765 million yuan, an increase of $77.8 \%$. The holiday of Tomb-sweeping Day witnessed a total of 1.2376 million tourists, an increase of 61.16\%, achieved comprehensive tourism income of 769 million yuan, an increase of $60.2 \%$. Dragon Boat Festival brought 1.639 million tourists to Zunyi, an increase of 38.3\%, comprehensive tourism income of 896 million yuan was achieved, an increase of 41.5\%. During Mid-Autumn Festival, Zunyi received a total of 1.756 million tourists, achieved comprehensive tourism income of 1.295 billion yuan. The holiday of National Day (October 1st) brought 5.492 million tourists to Zunyi, comprehensive tourism revenue of 3.83 billion yuan, respectively a growth of $46.6 \%$ and $48.7 \%$. Taking the 2016 Spring Festival tourism as an example, holiday tourism presents the following characteristics: the key scenic spots, new tourist attractions shows a growth of spurt reception; new types of tourists such as foreign tourists, overnight visitors, and self-driving tourists increase significantly; tourism consumption continues to expand, the average occupancy rate of star hotels in Zunyi is more than $80 \%$, and the diversification of tourism products and the enrichment of tourism products are desired; hot spring tour is extremely hot, rural tourism shows rapid growth; cultural activities become popular.

Construction of tourist attractions in Zunyi flourished. On January 26, 2013, Guizhou provincial government acting governor Chen Miner proposed in the Government Work Report to focus on creating 100 tourist attractions based on the deep integration of culture and tourism, emphasizing innovative tourism industry and changing development mode, strengthening the quality and brand building of tourist attractions, digging the cultural connotations of each tourist attractions, creating famous tourist destinations, improving the competitiveness and driving force of tourism industry. On March 1, 2013, Guizhou Provincial People's Government Office issued the 100 Tourist Attractions in Guizhou Province Construction Scheme in 2013, among which 17 tourist attractions in Zunyi were took into, involving an investment of 5.451 billion yuan. Right now, the finished projects include Zunyi Red Tourism Complex, Maotai Town Tourism Complex, Meitan Tea Leisure Resort Area, Wuchuan Gelao Cultural Tourism Scenic Spot, Zunyi City Hailong Ancient Military Castle. 
Red Tourism experienced strong growth. Zunyi is the capital of revolution, a city witness the turning point of Chinese revolution, closely related with Chinese revolutionary history, which is also the advantage of Zunyi tourism development. A lot of famous revolutionary issues such as Zunyi Meeting, Crossing Wujiang River, Loushanguan Victory, Four Times Crossing Chishui River happened in Zunyi. As a number of the first batch of historical and cultural cities, Zunyi was assessed by the National Tourism Administration as one of the Top Ten Red Tourism Bases, as well as one of the Twelfth Key Red Tourist Areas. Zunyi covers almost 100 red tourism resources, among which, the most famous one is the relics of Zunyi Meeting, enjoying high reputation around the world. Taking the Zunyi Meeting Memorial as an example, related 13 red tourist attractions include the Site of Zunyi Meeting, the Residence of Comrade Mao Zedong, Zhang Wentian and Wen Jiaxiang during the Period of Zunyi Meeting, the Site of the General Politial Department of the Red Army, the Red Army General Assembly Hall, the Residence of Comrade Deng Xiaoping, the Red Army Martyrs Cemetery and so on. This area received 13,800 tourists during the New Year's Day of 2016, a total of 74,000 tourists during the Spring Festival of 2016 with comprehensive tourism income of 46 million yuan, respectively an increase of $40.3 \%$ and $39.8 \%$. The number of tourists increased to 81,100 in the Tomb-Sweeping Day of 2016.

Rural eco-tourism develops with a sound momentum. Zunyi depends on rural resources such as agricultural production, peasant life, rural scenery, and folk culture to develop its rural tourism, belonging to the range of suburban tourism. Recently, tea culture emerges to be the highlight in Zunyi tourism industry. Meitan, Fenggang and other tea-producing counties, relying on tea industry, vigorously develop tea culture-related tourism resources, in order to achieve collaborative development of tourism, culture and tea industry. Furthermore, the unique folk customs, ecological environment, and leisure agriculture also attracts numerous visitors. For example, the Spring Festival of 2015 brought 17,100 tourists to visit Yuqing Feilongzhai Scenic Spot, and 14,500 tourists to Wuchuan Longtan Gelao Dansha Village.

The collaborative development of alcohol culture and tourism is another feature of Zunyi's tourism industry. Zunyi is the hometown of our national alcohol Moutai, enjoying the reputation of world famous alcohol city. Hence, Zunyi owns superior conditions to develop alcohol culture leading tourism. Alcohol culture and tourism have integrated for a long time, enriching each other's cultural connotation. Specifically, the experience function, entertainment function, esthetic function and economic function of alcohol culture tourism could transfer the geographical resources superiority into economic superiority, promoting regional economy development. Renhuai and Kweichow Moutai Group are the bridgeheads and vanguard of Zunyi alcohol culture tourism. In 2005, Kweichow Moutai Group was approved to be the national industrial tourism demonstration site. In 2011, Renhuai alcohol industrial tourism service standard project was approved by the National Standardization Commission, being set as the national service standardization pilot, exerting influence for national alcohol industrial tourism. The Guizhou Small Town Construction and Development Assembly held on August 21, 2012 proposed to create Maotai Town as the top one cultural tourism town in Guizhou, first class in China, and famous in the world, including 64 projects with investment of 25.689 billion yuan. The establishment of Maotai Town adds a lot of glory to alcohol tourism and further promotes the rapid development of alcohol tourism and industrial tourism.

\section{Existing Problems in the Development of Tourism Industry}

Zunyi tourism encounters poor location conditions and lagging infrastructure construction. The special geographical location of Zunyi endows the city rich tourism resources, but also constraints, such as the inconvenience transportation, which is the major bottleneck for tourism development. These constraints include internal constraints and external constraints. Internal constraints mainly manifested in the long period, high consumption, and more investment in the construction of railway, highway, and airport, due to the geographical conditions; the external constraints primarily displayed in the unsuccessful conjunction of Zunyi's transportation with the outside transportation, which is also the weakness of the whole Guizhou area. The late and slow development of Zunyi 
tourism leads to the lagging of infrastructure construction; the lack and imperfection of hotels, restaurants, shopping places, and entertainment could not satisfy the basic demands of tourists; the equipment and facilities of many scenic spots are either could not satisfy demands or lack of maintenance, forcing the equipment either too old or unqualified to be used; the design of facilities is unreasonable, without practical and functional considerations; unsecure factors still exist in scenic tour trails, guardrails and so on. Specific examples also include substandard catering and health conditions, lack of health and medical facilities in tourist attractions.

The tourism management capacity is weak. China's tourism is mainly led by government, which means government plays a key role in the management of tourism and directly determines the prospects of tourism. Zunyi government uses administrative means to replace the market regulation to run tourism. First, The highly centralized mode of government management, using administrative decree that emphasize the will of executive leadership to guide and operate tourism, will definitely ignore the rules and regulatory functions of the tourism market, and lead to excessive intervention of administrative units. Second, the tourism management organization does not have a clear structure with defined functions. In most cases, an all-round government stands out to replace the government-led, market-regulated tourism economy. Third, there is a multi-channel management situation in Zunyi tourism industry. On the one hand, several administrative organizations are repeatedly set and own overlap functions; on the other hand, evasiveness occurs when some problems happen. Fourth, administrative organization is seriously lagging behind in terms of information collection, analysis, processing, and dissemination, especially in the era of Internet + and in the information society, which prevent Zunyi tourism administration from accurately figuring out and effectively making use of the roles hiding behind the tourism market. Fifth, Zunyi government's poor performance in supervising tourism industry leads to irregular conducts in tourism resource developing and cultural tourism market developing. Sixth, Zunyi tourism industry is eager for talents. The development of tourism requires a professional talent team with solid professional quality and management experience, working at every link of the tourism industry.

The comprehensive service level is unqualified. Improving the comprehensive service level is urgent to promote the healthy development of Zunyi's tourism industry. Such improving solutions include enhancing public information services such as making full use of radio, television, SMS, network and other means to disseminate traffic, accommodation, travelling, weather, health and other relative information to facilitate travelling arrangement, as well as establishing a rapid and effective early warning mechanism to do the weather, natural disasters, health, safety and other early warning and forecasting work during holidays. The service quality of Zunyi's tourism industry still could not catch up with its developing pace. Besides the unqualified comprehensive services, some deep-seated problems are far from being solved, and some undesirable phenomena, such as illegal operation of some tour guides and travel agencies and compulsive shopping, are still prevalent.

The ineffective tourism brand building and poor publicity also are serious shortcomings of Zunyi tourism industry. Among Zunyi's tourism brands, red tourism is an important but also a defective one. On the one hand, Zunyi owns rich red tourism resources, but does not account for a clear competitive advantage compared to its counterparts due to its location and poor brand awareness. On the other hand, Zunyi Meeting, Four Times Crossing Chishui River, Crossing Wujiang River, Loushanguan Victory are valuable Long March cultural tourism boutique and brand, but only Zunyi Meeting is popular, the others are not so familiar for tourists. In a word, Zunyi only focuses on the promotion of such famous brands as Zunyi meeting and Moutai, instead of creating a complete set of red tourism brands, which lead to biased recognition of Zunyi tourism value, and ignoring, or even unheard of other brands.

The exploring degree of Zunyi tourism product still needs improving. Tea culture tourism is an example of Zunyi's incomplete exploring in terms of tourism product. Zunyi owns rich historical heritage and folk custom foundation of tea, but the tea cultural tourism development is only restricted to the simple stage of appreciating and drinking tea, neglecting to explore the connotation of tea culture, enhance its cultural added value, and enrich the contents of tea cultural tourism. The 
stereotyped development of tourism resources makes Zunyi lose its uniqueness, competitiveness and attractiveness.

Zunyi's tourism system is imperfect, and its resource advantage transformation rate is low. The imperfection of Zunyi's tourism system leads to the low transformation of its resource advantage to economic efficiency. Besides some red tourism resources, other tourism resource is late to develop and lack of deep exploring and systemic promotion. Compared with China's other tourism area, Zunyi's whole tourism industry, either human tourism resource, or natural eco-tourism resource, is incompletely developed, and still does not form a comprehensive system. Correspondingly, the transformation from resource advantage to economic advantage still needs further development and utilization.

\section{The Development Mode of Zunyi Tourism Industry}

China;s tourism industry is developed in government-led mode. In 1997, the National Tourism Administration officially confirmed tourism industry as one of the few government-led industries in China. Up to now, 30 provinces has set tourism as their local pillar industry, taking efforts to promote its development.

Zunyi also adopts government-led mode of tourism industry. The reason to form this mode is in the following: first, it is due to the strong performance concept of government and the governance practices. In the process of governance, the government's strong influence affects from the planning of scenic spots, the construction of scenic spots, and the design of tourist routes, to the management of scenic spots, the accommodation, and even transportation. Sometimes, even some unworthy tourism projects could be launched by the power of government. Second, it is determined by Zunyi's tourism resource. Zunyi Conference Memorial and other red tourism resource is one brand, which is advanced by the power of government instead of market. Such similar examples also include tea cultural tourism and alcohol cultural tourism. In addition, other tourism resource like widely distributed eco-tourism resource needs the help of the government's strong power. The reality of tourism resources restricts the choice of the government-led mode, which in turn further restricts the effective development and utilization of tourism resources. Government-led mode has many shortcomings, the most important of which is to misunderstand the government leading as government domination, replace market rules by executive orders, leading to decision-making errors, tourism supply and demand imbalance. Furthermore, misunderstanding government is responsible for all, including government's financial allocation of all, such as investing and directly managing the backbone tourism enterprises.

In essence, the main purpose of government-led mode is to give full play to the government's leading capacity under the precondition of market-based allocation of resources, actively guide and standardize the behavior of the tourism market through industrial policy, to achieve optimal or near optimal state in terms of production elements allocation, to achieve healthy, rapid and sustainable development of tourism. The market-oriented mode insists that the development of the tourism industry mainly depends on the market regulation mechanism to realize reasonable allocation of tourism resources through the market mechanism of price, supply and demand, and self-balancing. In the market-oriented mode, the government indirectly affects the development of tourism mainly through a certain market parameters. The essential difference between these two development modes is the role of the government in the operation of the tourism economy: either dominant or auxiliary. To promote the rapid development of tourism industry in Zunyi, we must change the development mode to market-oriented mode.

\section{Strategic Ways of Zunyi Tourism Industry}

Zunyi should create a good tourism investment environment and broaden the tourism investment channels. First of all, Zunyi should establish a sound investment guidance mechanism, including making a unified tourism investment planning and confirming priority development and investment projects; establishing a tourism investment guidance mechanism to guide the capital flow; making 
full use the role of government supervision to supervise the behavior of investment enterprises; and building information platform of tourism investment projects. Second, Zunyi should adjust the investment structure, including promoting the rational distribution of tourism investment within the region and the regional tourism industry, and focusing on special tourism product development and expansion. Third, Zunyi should broaden the financing channels, establish entrusted investment intermediary and tourism industry development fund; make full use of the capital market to raise tourism development funds through multi forms and multi channels. Fourth, Zunyi should pay attention to the comprehensive improvement of the external tourism investment environment.

Zunyi should accelerate the pace of tourism infrastructure and optimize the tourism environment. Such measures include building safe, convenient and efficient three-dimensional tourism transportation system; building tourism public information platform to provide basic services information for the society, market, tourists, related enterprises, and practitioners; optimizing, improving and standardizing Zunyi tourism guidance system; as well as increasing the protection of tourism resources and environment governance efforts.

Zunyi should establish sophisticated tourism organizing and managing system. On the one hand, all levels of Zunyi's government should accelerate the construction of tourism managing system, set up the people-oriented management concept of serving people and sustainable development, transfer its function to serve the society, adhere to ruling by law, strengthen administrative supervision, speed up the construction of tour guides and improve their overall quality, launch e-government construction, and improve the tourism administrative network. On the other hand, Zunyi should promote the establishment of tourism industry associations, especially municipal level and district (county) level associations, constituting a comprehensive coverage of broader industry associations. Associations should carry out extensive activities to improve services of tourism industry, collect and share information. At the same time, these associations should execut strict disciplines and get supports from government.

Zunyi should enhance the efforts of tourism brand building and publicity. Zunyi should intensify efforts to build red tourism brand, create alcohol cultural tourism and industrial tourism routes with the help of the reputation and attractiveness of Kweichow Moutai, build the Chishui "Danxia Landform Heritage” brand to carry out geographical and eco-tourism, build "China's Tea Sea” tea cultural tourism brand to realize collaborative development of both tea industry and tea cultural tourism, build "Origin of Gelao" brand to display the ethnic customs of the ethnic minority in Qianbei area, and build "Wujiang Gallery" eco-tourism brand. Publicity should also be increased at the same time of building tourism brands. First, governments and related enterprises should pay attention to tourism brand publicity. Second, a variety of promotional methods should be used. Third, Zunyi should adopt the walking out strategy to promote Zunyi's tourism advantages to domestic and abroad citizens. Fourth, Zunyi should strengthen brand culture construction, extract the core value and cultural spirit of Zunyi tourism brands to enhance their core competitiveness.

Zunyi should vigorously develop and improve the tourism product system. Zunyi tourism product development and tourism system construction must adhere to the following principles: First, the market principle. Tourism products must be developed in accordance with market demand in order to obtain good economic returns. Second, boutique and diversity principles. Zunyi should draw attention to the integration of Zunyi tourism resources, focus on the development of boutique tourism, introduce several high-grade tourism brands with complete supporting facilities, advanced management, superior services, establish market image and expand the influence of tourism products in Zunyis. Third, complementarity principle. When designing tourism products, the limitations of administrative divisions should give way to the concept of tourism space development, trying to avoid similar products with neighbors. At the same time, it should try to form a complementary relationship with the surrounding tourism products.

Zunyi should promote industrial integration and regional economic development. Industrial integration is an important way to develop tourism in Zunyi. On the one hand, all the sectors in tourism industry including accommodation, transportation, shopping, and entertainment should realize collaborative development. On the other hand, tourism industry should integrate with other 
industries, such as integration between alcohol cultural tourism and brewing industry, between tea cultural tourism and tea industry, between ecological agriculture tourism and leisure agriculture, between tourism and cultural \& creative industry, between exhibition tourism and specific industries. These integrations not only could promote industrial development, but also could aid the development and progress of regional economy, which in turn could support integrations. The above integrations and regional economy form cycle development model to promote and support each other, making contribution to both tourism development and rapid economic and social development.

Zunyi should strengthen the tourism market expansion and innovation. First of all, Zunyi government should raise awareness, strengthen policy guidance, and provide sound policy and social environment for tourism market. Second, tourism enterprises should change the way of thinking, concentrate to improve business grade, carry out innovative actions in terms of operation and developing new products, and avoid price competition through differentiation. Third, Zunyi should make innovative development strategies to stimulate consuming demand. Such innovation should be displayed in tourism product development, tourism product pricing, marketing channels, marketing communication, promotion portfolio strategy and so on. Specifically, practical actions should be taken from the following aspects: 1) relying on the resources advantages and fully mobilizing the positivity and initiative of county and district level tourism sectors are necessary for tourism marketing. 2) The fundamental purpose of tourism industrial linkage is to enhance publicity and reputation, to attract tourists. So in tourism promotion, it is essential to effectively deliver relevant tourism product information to potential tourism consumers and let them accept the information easily and willingly. 3) Tourism linkage should aim at target source market, especially strengthening connection and linkage with tourism administrative departments, key travel agencies, self-driving tour clubs, large enterprises, news media, could effectively expand the target source market.

\section{References}

[1]Gholam Reza Taleghani, Ali Ghafary, Seyed Esmail Asgharpour, et al. An investigation of the barriers related to tourism industry development in Iran [J]. Procedia - Social and Behavioral Sciences, 2014, 120(3):772-778.

[2]Hsin-Jung Hsieh, Shiann-Far Kung. The linkage analysis of environmental impact of tourism industry [J]. Procedia Environmental Sciences, 2013, 17:658-665.

[3]Zeng-Xian Liang, Tak-Kee Hui. Residents' quality of life and attitudes toward tourism development in China [J]. Tourism Management, 2016, 57:56-67.

[4]Ahmet Bulent Ozturk, Mathilda van Niekerk. Volume or value: a policy decision for Turkey's tourism industry [J]. Journal of Destination Marketing \& Management, 2014, 3(4):193-197.

[5]Xin-jian Li, Songshan (Sam) Huang, Chang-yao Song. China's outward foreign direct investment in tourism [J]. Tourism Management, 2017, 59:1-6. (In Progress)

[6]Zhan-feng Guo, Li Sun. The planning, development and management of tourism: The case of Dangjia, an ancient village in China [J]. Tourism Management, 2016, 56:52-62.

[7] Weiqing Meng, Lingying Xu, Beibei Hu, et al. Quantifying direct and indirect carbon dioxide emissions of the Chinese tourism industry[J]. Journal of Cleaner Production, 2016, 126:586-594.

[8] Jing Luo, Mu Zhang. Route Choice of low-carbon industry for global climate change: an issue of China tourism reform [J]. Energy Procedia, 2011, 5(3):2283-2288.

[9] Hengyun Li, Jason Li Chen, Gang Li, et al. Tourism and regional income inequality: Evidence from China [J]. Annals of Tourism Research, 2016, 58:81-99. 